\title{
Avaliação da atividade antimicrobiana do extrato hidroalcoólico das folhas de Petiveria alliaceae L. (Phytolacaceae)
}

\author{
Thaísa Vieira ANTUNES ${ }^{1}$ \\ Ronilson Ferreira FREITAS ${ }^{2}$ \\ Vanessa de Andrade ROYO ${ }^{3}$

\begin{abstract}
${ }^{1}$ Graduada em Farmácia pela Faculdade de Saúde Ibituruna - FASI. tati_va19@ hotmail.com
${ }^{2}$ Professor Substituto do Departamento de Farmácia e Mestrando em Saúde, Sociedade e Ambiente pela Universidade Federal dos Vales do Jequitinhonha e Mucuri - UFVJM. ronnypharmacia@gmail.com

${ }^{3}$ Doutora em Ciências Farmacêuticas pela Faculdade de Ciências Farmacêuticas de Ribeirão Preto/Universidade de São Paulo - FCFRP/USP. Professora do Programa de Pós-Graduação em Biotecnologia da Universidade Estadual de Montes Claros - Unimontes. Professora da Faculdade de Saúde Ibituruna - FASI e das Faculdades Integradas Pitágoras de Montes Claros - FIPMoc.
\end{abstract}

Recebido em: 03/09/2015 - Aprovado em: 18/02/2016 - Disponibilizado em: 30/07/2016

\begin{abstract}
RESUMO
Petiveria alliacea (Phytolacaceae) é uma planta herbácea nativa da floresta Amazônica e das áreas tropicais da América do Sul, Central, Caribe e África, de grande importância na medicina tradicional. P. alliacea, tem sido largamente utilizada na medicina tradicional para tratamento de diversas patologias, como artrite, reumatismo, malária, como antihelmíntica e antimicrobiana. Apesar da crescente produção de antibióticos pela indústria farmacêutica nas últimas décadas, a resistência microbiana a essas drogas também aumentou consideravelmente. Dessa forma, é de extrema importância comprovar a eficácia de plantas medicinais comumente utilizadas pela população com finalidade antimicrobiana. $\mathrm{O}$ presente trabalho objetivou avaliar a atividade antimicrobiana pela determinação da concentração inibitória mínima (CIM) do extrato hidroalcoólico das folhas de Petiveria alliaceae (guiné) frente aos microrganismos Escherichia coli (ATCC 25922), Pseudomonas aeruginosa (ATCC 27853) e Staphylococcus aureus (ATCC 6538). Os resultados encontrados foram considerados promissores, uma vez que foi observada atividade antimicrobiana sobre as bactérias $E$. coli e $S$. aureus, estando as concentrações inibitórias mínimas na faixa de 62,5-125 mg/mL e 125-250 $\mathrm{mg} / \mathrm{mL}$, respectivamente.
\end{abstract}

Descritores: Petiveria alliacea. Phytolacaceae. Plantas medicinais. Atividade antimicrobiana. Concentração inibitória mínima.

\section{Evaluation of the antimicrobial activity of the hydroalcoholic extract of leaves Petiveria alliaceae L. ( Phytolacaceae )}

\begin{abstract}
Petiveria alliacea (Phytolacaceae) is a herbaceous plant native Amazon rainforest and the tropical areas of South and Central America, the Caribbean and Africa, of great importance in traditional medicine. P. alliacea, has been widely used in traditional medicine for treatment of various diseases such as arthritis, rheumatism, malaria, as anthelmintic and antimicrobial. Despite increasing production of antibiotics by the pharmaceutical industry in recent decades, microbial resistance to these drugs has also increased considerably. Thus, it is extremely important to prove the effectiveness of medicinal plants commonly used by people with antimicrobial purpose. This study aimed to evaluate the antimicrobial activity by determining the minimum inhibitory concentration (MIC) of the hydroalcoholic extract of the leaves of Petiveria alliaceae (Guinea) against microorganisms Escherichia coli (ATCC 25922), Pseudomonas aeruginosa (ATCC 27853) and Staphylococcus aureus (ATCC 6538). The results were considered promising since it was observed antimicrobial activity against the bacteria $E$. coli and $S$. aureus, minimum inhibitory concentrations being in the range of 62,5 to $125 \mathrm{mg} / \mathrm{ml}, 125-250 \mathrm{mg} / \mathrm{ml}$, respectively .
\end{abstract}

Keywords: Petiveria alliacea. Phytolacaceae. Medicinal plants. Antimicrobial activity. Minimum inhibitory concentration . 


\section{INTRODUÇÃO}

Desde muitos anos que o uso de plantas medicinais como meio de cura ou prevenção de doenças, ocorre em todas as regiões do globo, variando regionalmente por influência de características culturais da população, assim como de sua flora, solo e clima (PUPPO; SILVA, 2008).

O uso da medicina tradicional e das plantas medicinais, em países em desenvolvimento, tem sido amplamente observado como base normativa para a manutenção da saúde (BRASIL, 2006; SILVA, 2006), onde o conhecimento sobre plantas medicinais simboliza muitas vezes o único recurso terapêutico de muitas comunidades e grupos étnicos (HOEFFEL et al., 2011).

No Brasil, é comum a utilização de plantas medicinais devido a forte influência cultural dos indígenas locais miscigenadas as tradições africanas, oriundas de três séculos de tráfico escravo e da cultura européia trazida pelos colonizadores (MAIOLIAZEVEDO; FONSECA-KRUEL, 2007). Os estudos etnobotânicos são importantes no Brasil, uma vez que seu território abriga uma das floras mais ricas do mundo, da qual $99 \%$ são desconhecidas quimicamente (GOTTLIEB et al., 1998)

A família Phytolacaceae, uma das constituintes da flora brasileira, possui cerca de dezessete gêneros e em torno de cento e vinte e cinco espécies amplamente distribuídos por regiões tropicais e subtropicais. Algumas espécies possuem propriedades comestíveis, medicinais e ornamentais (GOMES, 2006).

Dentre inúmeras plantas da família Phytolacaceae utilizadas na medicina caseira está a Petiveria alliacea (guiné) que é uma espécie nativa da floresta amazônica, e das áreas tropicais da América do Sul, central, Caribe e África. É uma planta herbácea, ereta, perene, rizomatosa, com leve aroma de alho, possui altura de cerca de $70 \mathrm{~cm}$, com flores discretas, dispostas em longas inflorescências racemosas. O fruto é uma cápsula pequena, cuneiforme e dotada de espinhos, que lhes servem como meio de propagação, já que se prendem facilmente em animais e em roupas de transeuntes. Possui sinonímia bastante diversificada sendo conhecida popularmente por guiné, tipi, amansa-senhor, erva-de-alho, gamba, raiz-de-congo, pipi, mucuracaá, paracoca, pau-de-guiné, entre outros nomes. Preparações a base de $P$. alliacea têm sido extensivamente utilizadas na medicina tradicional para o tratamento de muitas doenças (OLIVEIRA et al., 2010; GUEDES et al., 2009; LORENZI; MATOS, 2002).

$P$. alliacea, é largamente utilizada na medicina caseira como antiespasmódica, diurética, sudorífica e enemagoga, sendo usada na forma de infusão fraca das folhas ou das raízes contra hidropsia, artrite, reumatismo, malária, como abortiva e antimicrobiana (usada para afecções bucais e infecções de garganta na forma de chá por 
infusão), possui ainda atividade antineoplásica, anti-helmíntica, e sedativa. As raízes da $P$. alliacea, parecem ser mais ativas que as folhas, possuindo atividade analgésica e anestésica. Em doses elevadas ou repetidas ela é considerada tóxica. Por essa razão, no Brasil colonial ela era chamada de remédiode-amansar-senhor pelos escravos, devido aos efeitos sedativos e tóxicos. Devido aos efeitos tóxicos, deve ser usada cautelosamente e em doses intercaladas. De acordo com GOMES (2006), há relatos de quadros de caquexia muscular distrófica, caracterizada por debilidade dos membros inferiores, perda de peso, dilatação cardíaca e lesões renais (LORENZI; MATOS, 2002; GUEDES, 2009; GOMES, 2006)

O conhecimento acerca de determinadas espécies vegetais com propriedades antimicrobianas tem sido revisto, pois além do crescente problema de resistência bacteriana, a perspectiva futura para o uso de antibióticos é bastante incerta. A terapia para as infecções bacterianas e fúngicas, representa um desafio para muitos pesquisadores e clínicos (MACHADO, 2005). Componentes antimicrobianos presentes em plantas podem inibir o crescimento bacteriano e fúngico por diferentes mecanismos de ação possuindo um significativo valor clínico. As propriedades antimicrobianas de substâncias e óleos essenciais têm sido reconhecidas empiricamente durante séculos, mas foram confirmadas cientificamente apenas recentemente. No entanto uma grande diversidade de plantas medicinais ainda é utilizada no Brasil para o tratamento de infecções comuns, na forma de extrato bruto, infusões ou emplastos, sem nenhuma evidência científica de sua eficácia (PESSINI, 2003; GUEDES, 2009; DUARTE, 2006).

O presente trabalho objetivou avaliar a atividade antimicrobiana pela determinação da concentração inibitória mínima (CIM) do extrato hidroalcoólico das folhas de Petiveria alliaceae (guiné) frente aos microrganismos Escherichia coli (ATCC 25922), Pseudomonas aeruginosa (ATCC 27853) $e$ Staphylococcus aureus (ATCC 6538).

\section{METODOLOGIA}

\section{Coleta e identificação da espécie em estudo}

As amostras vegetais de Petiveria alliacea foram coletadas no mês de setembro de 2010, no município de Mortugaba - BA. As amostras coletadas foram acondicionadas em sacos plásticos, isentos de umidade e luz para realização das análises. Foram preparadas exsicatas e a identificação foi feita por comparação com material herborizado. As exsicatas estão depositadas no Herbário Montes Claros na Universidade Estadual de Montes Claros - UNIMONTES-MG. 


\section{Preparo do Extrato Bruto Hidroalcoólico}

A extração foi feita através da Extração em Soxhlet conforme ilustra a Figura 1.

Pesaram-se 100 gramas do material vegetal fresco em balança analítica e este foi colocado num cartucho de celulose dentro do Soxhlet. O solvente utilizado foi etanol 92,8\%, responsável pela extração. A extração foi realizada durante 6 horas e o extrato foi resgatado juntamente com a solução final do balão e posteriormente concentrada em evaporador rotativo, a baixa pressão. Para os testes extrato bruto foi diluído em tween 80 a $5 \%$ na concentração de $250 \mathrm{mg} / \mathrm{mL}$, as diluições foram feitas à partir desta.

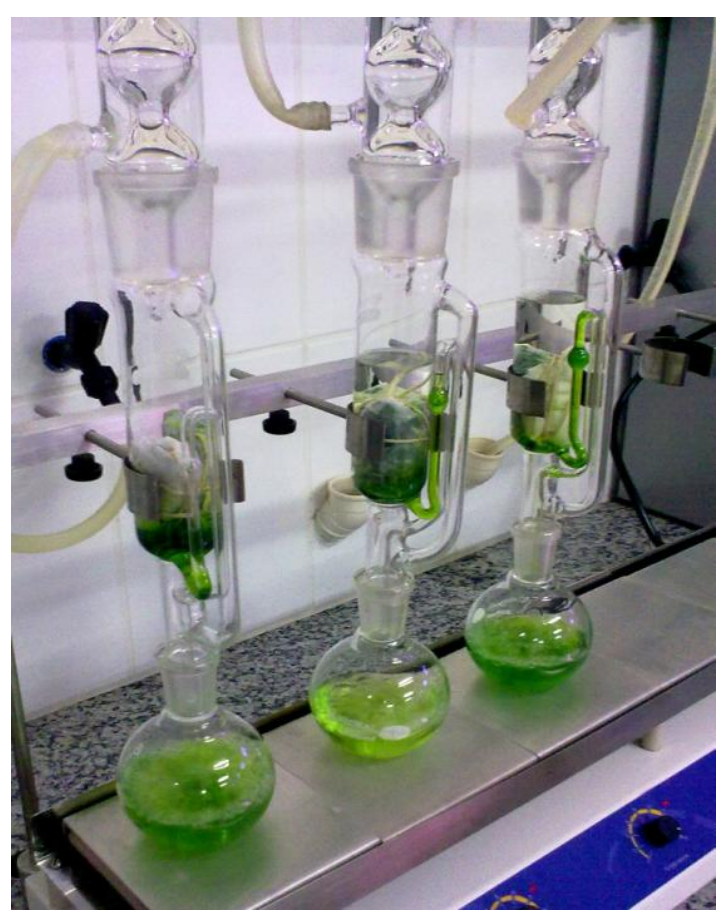

Figura 1: Extração de Soxhlet (Fonte: Arquivo do autor)

\section{Microrganismos utilizados}

A avaliação da atividade antimicrobiana foi realizada com cepas adquiridas no arquivo de bactérias do Laboratório de Microbiologia da Faculdade de Saúde Ibituruna - FASI. Foram utilizadas as seguintes bactérias para testar o EB: Escherichia coli (ATCC 25922), Pseudomonas aeruginosa (ATCC 27853) $e$ Staphylococcus aureus (ATCC 6538).

\section{Preparo do inóculo}

O desenvolvimento das culturas de bactérias foi realizado em meio de cultura Ágar soja tripticaseína (AST) por 24 horas. Posteriormente essas culturas foram padronizadas em solução salina segundo a turbidez de 0,5 da escala de MacFarland $\left(10^{-8}\right.$ UFC/mL - 0,1 mL de Cloreto de Bário a $1 \%$ e 9,9 mL de ácido sulfúrico a $1 \%$ ) por meio das absorbâncias em $650 \mathrm{~nm}$.

\section{Avaliação da Atividade Antimicrobiana}

Os ensaios de sensibilidade de microdiluição em caldo foram feitos em triplicata, utilizando microplacas de 96 poços, seguindo as recomendações da NCCLS (2005). Esse método permite determinar a CIM, que é a menor concentração do extrato capaz de inibir o crescimento bacteriano (NCCLS, 2005). Antes do teste as placas foram esterilizadas com hipoclorito 5\% durante 24 horas e, em seguida, lavadas com água deionizada e submetidas à luz UV (254 nm) durante 30 minutos. Em cada poço foi 
adicionado $100 \mu \mathrm{L}$ de caldo Mueller-Hinton. Em seguida, foram adicionados no primeiro poço $50 \mu \mathrm{L}$ do respectivo extrato com concentração conhecida, sendo realizada uma diluição seriada do poço A1 ao poço A12, sucessivamente, conforme a Figura 2.

Posteriormente, foram adicionados a cada cavidade $50 \mu \mathrm{L}$ do inóculo. Como controles positivos foram utilizados os antibióticos gentamicina, oxacilina e ceftazidima para E. coli, S. aureus e $P$. aeruginosa, respectivamente. Em um orifício de cada placa fez-se o controle da cultura (ausência de agente antimicrobiano). Em outro orifício fez-se o controle de esterilidade do ágar Mueller-Hinton, em outro o controle do sistema solvente utilizado na solubilização do extrato e dos microrganismos isolados e em outro o controle do extrato. As microplacas foram seladas com parafilme e após 24 horas de incubação a $35 \pm 2{ }^{\circ} \mathrm{C}$ foi adicionado em cada poço $30 \mu \mathrm{L}$ de solução aquosa de resazurina a 0,02\% (Figura 3). As microplacas foram incubadas por mais 60 minutos e, em seguida, realizada a leitura visual. A manutenção da cor azul nos orifícios é interpretada como ausência de crescimento microbiano (microrganismo sensível à substância avaliada) e a cor vermelha/rosa indica presença de microrganismo no meio.

\section{RESULTADOS E DISCUSSÃO}

Para Alves et al., (2008) e Andrews (2001) a CIM é a menor concentração de um agente antimicrobiano capaz de inibir o crescimento de um organismo. As CIM's são consideradas excelentes ferramentas para determinar a susceptibilidade dos organismos aos antimicrobianos e determinar a atividade in vitro de novos antimicrobianos.

Para Duarte (2006) não existe um consenso sobre o nível de inibição aceitável para produtos naturais quando comparados com antibióticos padrões, tanto que alguns consideram somente resultados similares aos dos antibióticos, enquanto outros consideram com bom potencial mesmo aqueles com níveis de inibições inferiores. Os resultados da CIM encontram-se dispostos na Tabela 1. 


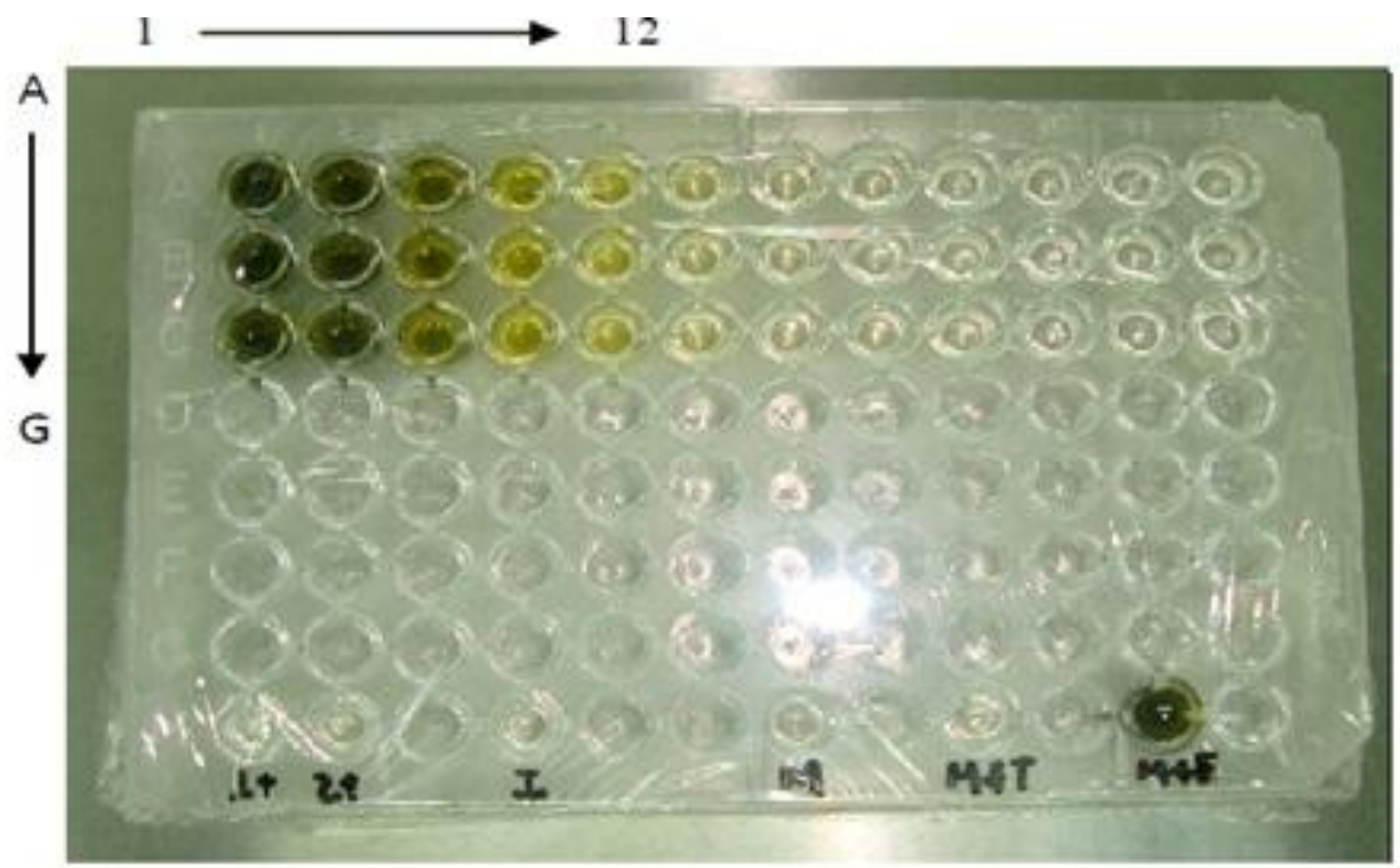

Figura 2: Microplaca de Elisa e indicações das aplicações nos poços (Fonte: arquivo do autor)

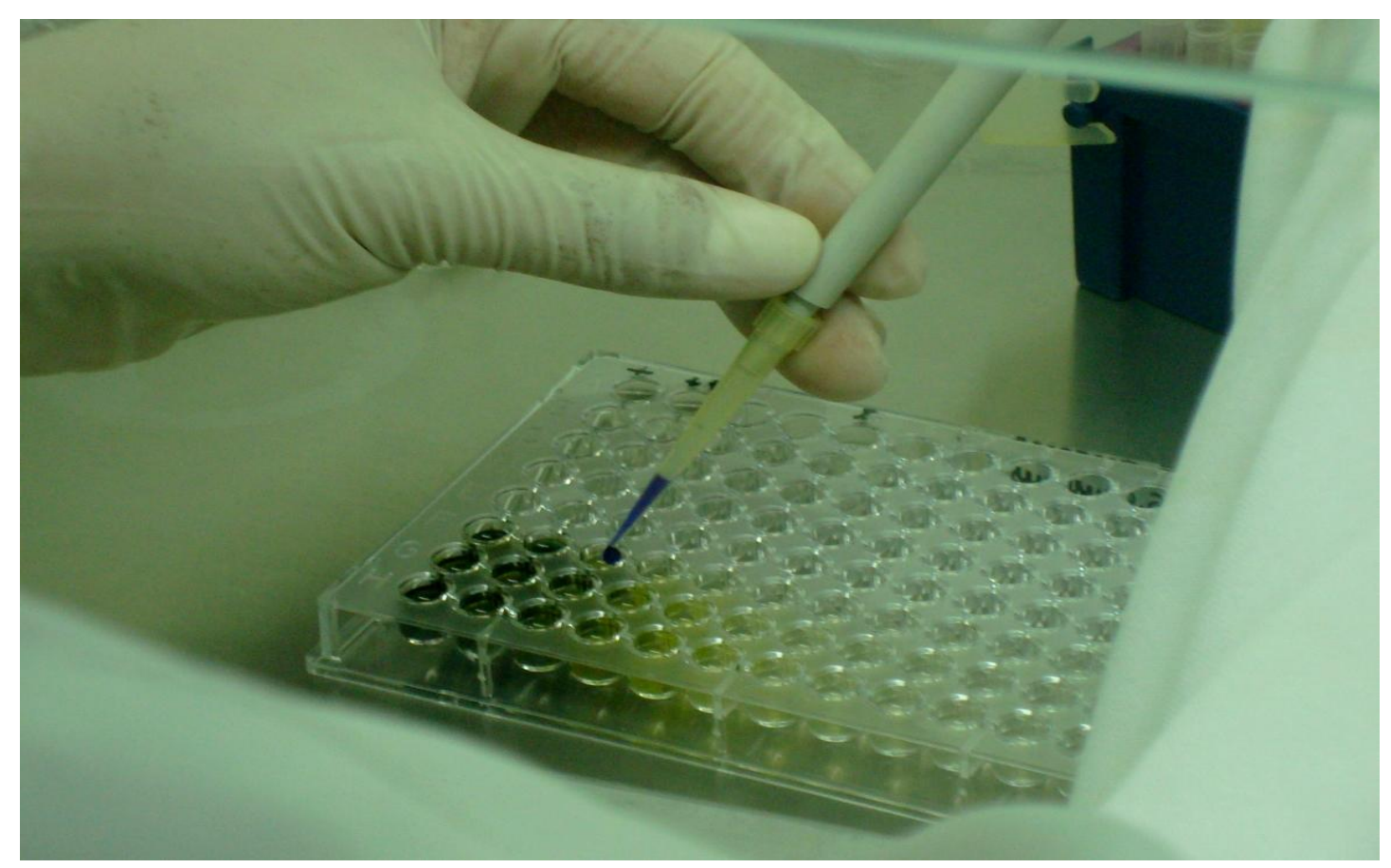

Figura 3: Aplicação da solução aquosa de resazurina $0,02 \%$ (Fonte: Arquivo do autor). 
Tabela 1: Valores de CIM obtidos para o EBF.

\begin{tabular}{cc}
\hline Bactéria & CIM $(\mathbf{m g} / \mathbf{m L})$ \\
\hline Escherichia coli & $62,5-125$ \\
Staphylococcus aureus & $125-250$ \\
Pseudomonas aeruginosa & $*$ \\
* P. aeruginosa apresentou resistência à todas as concentrações utilizadas.
\end{tabular}

As Figuras 4 e 5 apresentam os resultados obtidos a partir da revelação com a solução de resazurina a $0,02 \%$.

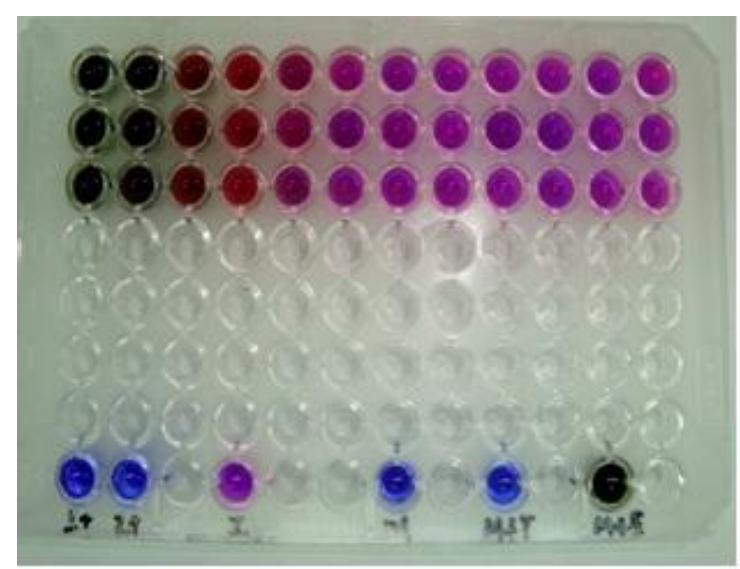

Escherichia coli

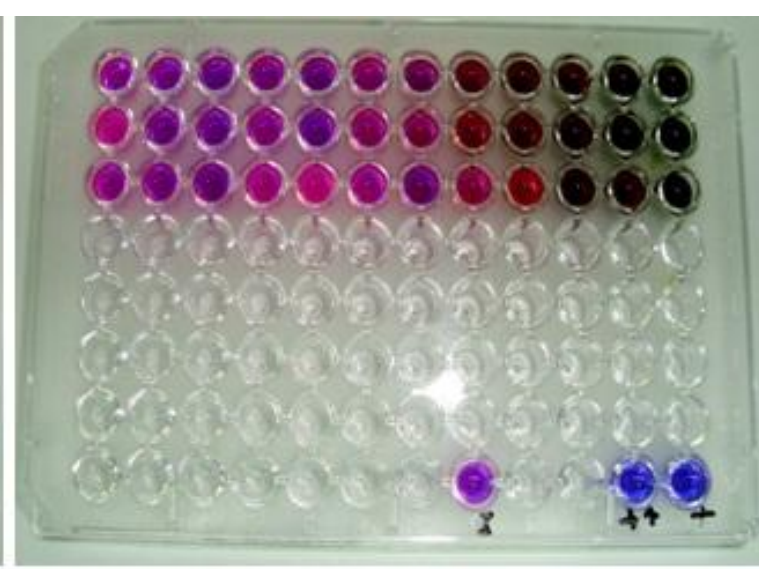

Staphylococcus aureus

Figura 4: Determinação da CIM - E. coli e S. aureus (Fonte: Arquivos do autor)

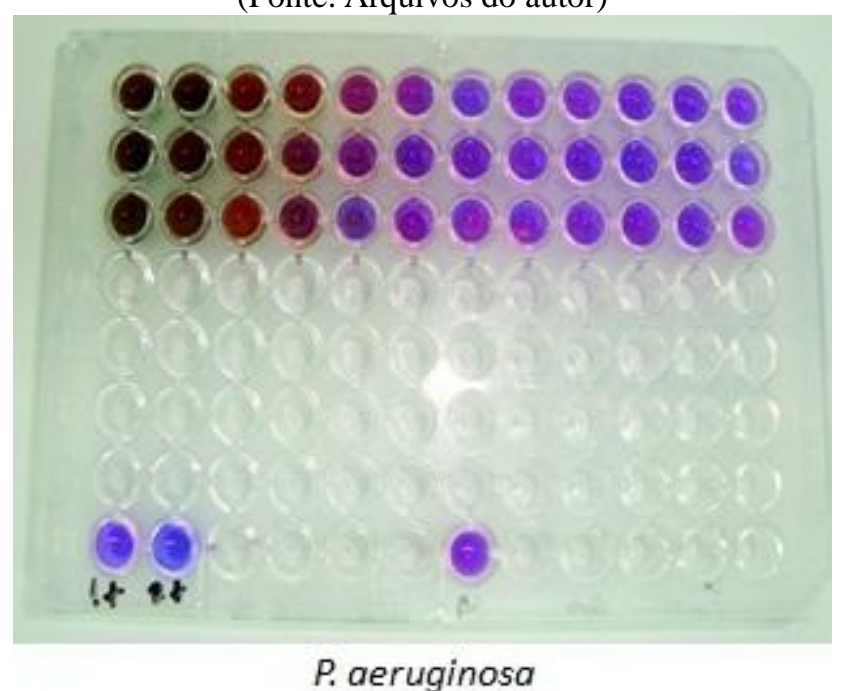

Figura 5: Determinação da CIM - P. aeruginosa (Fonte: Arquivos do autor) 
A remoção do etanol através da evaporação rotativa foi importante uma vez que evitou que sua atividade bacteriostática mascarasse propriedades antimicrobianas do extrato vegetal.

Kubec (2003) isolou um óleo ardente de cor amarela estimulante do sistema lacrimal de Petiveria alliaceae e avaliou atividade antimicrobiana frente a vários microrganismos. O $S$. aureus apresentou inibição na concentração de $100 \mu \mathrm{g} / \mathrm{mL}$ e $E$. coli com concentração de $40 \mu \mathrm{g} / \mathrm{mL}$. Para a $P$. aeruginosa não foi observada inibições, dessa forma, esses resultados concordam nitidamente com os resultados deste estudo. Em outro trabalho realizado por Guedes et al. (2009), os resultados encontrados também estão em concordância com os resultados aqui apresentados. A determinou a CIM de $P$. alliaceae, foi determinada empregando-se diferentes soluções extrativas (hexano, álcool metílico, álcool etílico, etanol $70 \% \mathrm{v} / \mathrm{v}$ e água purificada). Os resultados encontrados demonstraram que os extratos etanólicos à $70 \%$ possuem amplo espectro de ação antimicrobiana, provavelmente relacionada com a maior quantidade de polifenóis totais e flavonóides totais obtidos para esse extrato (GUEDES et al., 2009).

Contudo, é valido lembrar que se o extrato bruto possui atividade antibacteriana, algum ou vários constituintes do mesmo atuam nessa função. Este resultado reforça a hipótese de sinergismo (combinação de compostos potencializando determinado efeito) conforme resultados encontrados por Nascimento et al. (2008), Muller (2006) e Carvalho (2009).

Portanto, com a atividade do extrato bruto hidroalcoólico comprovada frente a cepas ATCC, é necessário buscar métodos de extração a fim de verificar a existência de partição ou até mesmo um composto ativo que seja mais eficiente que o extrato bruto.

\section{CONCLUSÃO}

O extrato bruto hidroalcoólico de folhas de $P$. alliacea apresentou atividade antimicrobiana contra $S$. aureus e E. coli, sendo capaz de inibir o crescimento desses microrganismos, evidenciando seu potencial bacteriostático. Os resultados aqui apresentados são promissores e justificam a realização de futuros estudos visando a semipurificação de frações bioativas, bem como a avaliação in vivo da atividade antimicrobiana e a realização de estudos toxicológicos com extratos e frações de $P$. alliacea.

\section{REFERÊNCIAS}

ALVES, E. G.; VINHOLIS, A. H. C.; CASEMIRO, L. A.; ARAÇARI, N. Estudo comparativo de técnicas de screening para avaliação da atividade antibacteriana de extratos brutos de espécies vegetais e de 
substâncias puras. Revista Química Nova. v. 31, n. 5, p.1224-1229, 2008.

ANDREWS, J. M. Determination of minimum inhibitory concentrations. Journal of antimicrobial chemotherapy. v. 48, n. 1, p.5-16, 2001.

BRASIL. Ministério da Educação. A fitoterapia no SUS e o programa de pesquisas de plantas medicinais da central de medicamentos. Brasília, DF: Ministério da Saúde, 147p, 2006.

\section{CARVAlHO, M. S. Potencial}

antimicrobiano de extratos brutos, semipuros e compostos flavônicos isolados da aroeira-preta (Myracrondruon urundeuva Fr. All.) contra cepas bacterianas de importância clínica. 2009. 100 p.

Dissertação (Mestrado em Ciências Biológicas) - Universidade Estadual de Montes Claros, Montes Claros, 2009.

DUARTE, M. C. T. Atividade antimicrobiana de plantas medicinais e aromáticas utilizadas no Brasil. Rev. MultiCiência: Construindo a História de Produtos Naturais. n. 7, p. 116, 2006.

GOMES, P. B. Avaliação dos efeitos centrais e antinociceptivos das frações isoladas da raíz de Petiveria Alliacea $\mathbf{L}$. (Tipi) em camundongos. 2006. 174 p. Dissertação (Mestrado em Farmacologia) -
Universidade Federal do Ceará, Fortaleza, 2006.

GOTTLIEB, O. R.; BORIN, M. R. M. B.; PAGOTTO, C. L. A. C.; ZOCHER, D. H. T. Biodiversidade: o enfoque interdisciplinar brasileiro. Ciência \& Saúde Coletiva. v. 3, n. 2, p. 97-102, 1998.

GUEDES, R. C. M.; NOGUEIRA, N. G. P.; FUSCO-ALMEIDA, A. M.; SOUZA, C. R. F.; OLIVEIRA, W. P. Atividade antimicrobiana de extratos brutos de Petiveria alliacea L. Latin American Journal of Pharmacy. v. 28, n. 4, 2009.

HOEFFEL, J. L. M.; GONÇALVES, N. M.; FADINI, A. A. B.; SEIXAS, S. R. C. Conhecimento tradicional e uso de plantas medicinais nas APAS'S Cantareira/SP e Fernão Dias/MG. Revista VITAS - Visões Transdisciplinares sobre Ambiente e Sociedade. n. 1, p. 1-25, 2011.

KUBEC, R; KIM, S.; MUSAH, R. A. The lachrymatory principal of Petiveria alliacea. Phytochemistry. v. 63, p. 37-40, 2003.

\section{LORENZI, H; MATOS, F. J. A. Plantas} medicinais no Brasil: nativas e exóticas. Nova Odessa, SP: Instituto Plantarum, 512 p. 2002.

MACHADO, K. E. Atividade antimicrobiana dos extratos, frações e 
substâncias isoladas da Eugenia

umbelliflora Berg. 2005. 71 p. Dissertação

(Mestrado em Ciências Farmacêuticas) -

Universidade do Vale do Itajaí, Itajaí, 2005.

MAIOLI-AZEVEDO, V.; FONSECA-

KRUEL, V. S. Plantas medicinais e

ritualísticas vendidas em feiras livres no

Município do Rio de Janeiro, RJ, Brasil:

estudo de caso nas zonas Norte e Sul. Acta

bot. bras. v. 21, n. 2, p. 263-275. 2007.

MULLER, J. B. Avaliação das atividades

antimicrobiana, antioxidante $\mathrm{e}$

antinociceptiva das folhas da Luehea

divaricata Martius. 2006. 100 p. Dissertação

(Mestrado em Ciências Farmacêuticas).

Universidade Federal de Santa Maria, Santa

Maria, 2006.

NASCIMENTO, J. E.; MELO, A. F. M.;

LIMA E SILVA, T. C.; VERAS FILHO, J.;

SANTOS, E. M.; ALBUQUERQUE, U. P.;

AMORIM, E. L. C. Estudo fitoquímico e

bioensaio toxicológico frente a larvas de

Artemia salina Leach. de três espécies

medicinais do gênero Phyllanthus

(Phyllanthaceae). Revista de Ciências

Farmacêuticas Básica Aplicada. v. 29, n. 2,

p. 145-150, 2008.
NCCLS. National Committee for Clinical

Laboratory Standarts. Normas de

desempenho para testes de sensibilidade

antimicrobiana. $15^{\circ}$ Suplemento

Informativo, v.25, 2005.

OLIVEIRA, G. L.; OLIVEIRA, A. F. M.;

ANDRADE, L. H. C. Plantas medicinais

utilizadas na comunidade urbana de

Muribeca, Nordeste do Brasil. Acta bot.

bras. v. 24, n. 2, p. 571-577, 2010.

PESSINI, G. L.; HOLETZ, F. B.; SANCHES,

N. R.; CORTEZ, D. A. G.; DIAS FILHO, B.

P.; NAKAMURA, C. V. Avaliação da

atividade antibacteriana e antifúngica de

extratos de plantas utilizados na medicina

popular. Revista Brasileira de

Farmacognosia. v. 13, n. 1, p. 21-24, 2003.

PUPPO, E.; SILVA, C. P. Levantamento do

perfil medicamentoso e freqüência de

associações entre o Ginkgo (Ginkgo biloba

L.) e ácido acetilsalicílico, em usuários

atendidos pela FarmaUSCS de São Caetano

do Sul. Rev. Ciênc. Farm. Básica Apl. v. 29, n.1, p. 53-58, 2008.

SILVA, P. Farmacologia. 7. ed. Rio de Janeiro: Guanabara Koogan, 1369 p. 2006. 